\title{
MEIO AMBIENTE E DIREITOS FUNDAMENTAIS: A QUESTÃO DOS REMOLDADOS E O DIÁLOGO ENTRE JURISDIÇÕES (ADPF 101 DE 2009)
}

\author{
ENVIROMENT AND FUNDAMENTAL RIGHTS: THE REMOLDED QUESTIONS AND \\ DIALOGUES AMONG AUTHORITIES.
}

Eduardo Biacchi Gomes

Doutorado em Direito pela Universidade Federal do Paraná (2003). É Pós-Doutor em Estudos Culturais junto à Universidade Federal do Rio de Janeiro, com estudos realizados na Universidade de Barcelona. Professor-adjunto integrante do quadro da UniBrasil , Graduação e Mestrado em Direito, da Pontifícia Universidade Católica do Paraná (professor titular). E-mail: ebgomes@me.com

Ronald Silka de Almeida

Mestre em Direito pelas Faculdades Integradas do Brasil, professor universitário.

Recebido em: 05.08.2015

Aprovado em: 18.02.2016

DOI:10.5585/rdb.v12i5.184

\section{RESUMO}

O presente artigo tem por objeto examinar a temática referente ao meio ambiente e o desenvolvimento sustentável dentro de um Estado democrático de direito. Para tanto, parte-se da concepção que a proteção ao meio ambiente é um direito fundamental das presentes e das futuras gerações e, como tal, torna-se necessário buscar a sua efetiva proteção sem, entretanto, inviabilizar o desenvolvimento do Estado brasileiro. Para tanto examina-se a dualidade: meio ambiente e desenvolvimento sustentável. Como forma de demonstrar a tese, ora expendida, buscar-se-á ilustrar o tema através do controverso caso dos remoldados e o chamado diálogo entre jurisdições.

Palavras-chaves: direitos fundamentais; desenvolvimento sustentável; controle de convencionalidade; diálogo entre jurisdições; comércio internacional.

\begin{abstract}
This article intends to examine the theme related to environment and sustainable development in a democratic state. For this purpose, we start from the conception that environmental protection is a fundamental right to the present and the future generations and, as such, it becomes necessary to seek for effective protection without, however,
\end{abstract}


derail the development of the Brazilian state. For that examines the duality: the environment and sustainable development. In order to demonstrate the thesis, now expended, will seek to illustrate the theme through-the controversial case of remolded and called dialogue between jurisdictions.

Keywords: fundamental rights; sustainable development; conventionality control; dialogue between jurisdictions; international trade.

\section{INTRODUÇÃO}

Inquestionavelmente, dentro dos Estados democráticos de direito, o meio ambiente deve ser elevado a categoria de direitos fundamentais, tendo em vista a necessidade de se garantir a máxima efetividade da proteção da norma jurídica, pois o meio ambiente - enquanto bem jurídico para a presente e futuras gerações - tem como principal destinatário não somente a pessoa humana, mas igualmente todos os seres vivos, eis que não se pode conceber a vida no planeta Terra sem a existência de um meio ambiente ecologicamente equilibrado.

Independentemente da existência de um ordenamento jurídico para proteger o meio ambiente, torna-se necessário a existência de uma consciência por parte do poder público no sentido da importância de se preservar o meio ambiente. O presente artigo efetua a análise histórica da formação do Estado constitucional de direito e a sua relação com a proteção ao meio ambiente.

A concepção notadamente histórica, destacada neste artigo, torna-se de grande importância para a análise do tema, de forma a demonstrar a íntima relação que a democracia e os direitos fundamentais possuem com a proteção ao meio ambiente.

A efetiva proteção ao meio ambiente ecologicamente equilibrado, além da existência de uma legislação que aplique sanções aos seus infratores, depende de uma atuação do Poder Judiciário, no sentido de se buscar o cumprimento dos preceitos constitucionais.

Como forma de ilustrar a análise contida no presente artigo, importante destacar o julgamento realizado perante o Supremo Tribunal Federal, na Ação de Descumprimento de Preceito Fundamental de n. 101/DF, julgado em 2009, em que proibiu-se a importação de carcaças de pneus com o objetivo da fabricação dos remoldados, tendo em vista a formação de grande passivo ambiental, demonstrando-se aqui que o chamado diálogo entre jurisdições e o controle de convencionalidade também se dá e temas conexos aos direitos humanos, como livre comércio e meio ambiente. 


\section{CONSTITUIÇÃO E DEMOCRACIA}

Concebe-se a democracia como aquele regime político que pressupõe a participação popular na formação da vontade estatal, então a questão do sujeito apresenta-se como central, posto que a participação nas decisões de ordem pública é precedida da integração de cada indivíduo no corpo político que toma as decisões que atingem a todos.

Conforme explica Raymond Aron1, em análise aos escritos de Alexis de Tocqueville, $[\ldots]$ "a democracia consiste na igualização das condições. Democrática é a sociedade em que não subsistem distinções de ordens e de classes; em que todos os indivíduos que compõem a coletividade são socialmente iguais, o que não significa que sejam intelectualmente iguais, o que é absurdo, ou economicamente iguais, o que, para Tocqueville, é impossível”.

Esclarece que em relação à mencionada igualdade social, não significa a inexistência de diferenças hereditárias de condições; mas "quer dizer que todas as ocupações, todas as profissões, dignidades e honrarias são acessíveis a todos. Estão, portanto, implicadas na idéia da democracia a igualdade social e, também, a tendência para a uniformidade dos modos e dos níveis de vida" 2 .

Assim, diante da citação de Tocqueville, podemos afirmar que o autor trata a democracia considerando-a como um governo para o povo, desde que a sociedade seja homogênea, ou seja, ela é inexistente em sociedades onde se acentuam as "diferenças religiosas, ideológicas, lingüísticas, culturais, étnicas ou raciais, originando subgrupos sociais quase separados".

Aliás, a interpretação majoritária, a definição básica de democracia é que esta significa "governo pela maioria do povo", e conforme explica Friedrich Muller3, "Democracia é uma das expressões mais indeterminadas, isto é, uma das expressões utilizadas dos modos mais distintos imagináveis, frequentemente opostos. De qualquer forma modo, a história do termo nos oferece os significados "governo" e "povo"; mas se isso resulta em algo como "governo do povo" é justamente a questão: ou melhor, já não

\footnotetext{
1 ARON, Raymond. As etapas do pensamento sociológico. tradução: Sérgio Bath. $7^{\mathrm{a}}$ ed. São Paulo: Martins Fontes, 2008. pp. 320-321.

2 ARON, Raymond. As etapas do pensamento sociológico. tradução: Sérgio Bath. $7^{a}$ ed. São Paulo: Martins Fontes, 2008. pp. 320-321.

${ }^{3}$ MULLER, Friedrich. Que grau de exclusão social ainda pode ser tolerado por um sistema democrático in: PIOVESAN, Flávia (Coord.) Direitos Humanos, Globalização Econômica e Integração Regional. Desafios do Direito Constitucional internacional. São Paulo: Max Limonad, 2002. p. 560..
} 
é mais a questão", mais adiante esclarece que a referência ao "povo" é mecanismo de legitimação, posto que "o sistema deve poder representar-se como se funcionasse com base na soberania popular e na autodeterminação do povo" 4 .

$\mathrm{Na}$ democracia devem existir a necessidade e a possibilidade "de controle efetivo e permanente dos governantes pelos governados5", passando de um Estado cujo poder decorre de uma soberania estatal, para a soberania de cunho popular, transformando os direitos dos súditos "em direitos do homem e do cidadão, ou seja, em direitos liberais e políticos de cidadania6".

que ao ser estabelecido é legitimado pelos cidadãos, seus autores.

Para Jürgen Habermas30, “o Estado constitucional democrático, de acordo com a ideia que o sustenta, é uma ordem desejada pelo próprio povo e legitimada pelo livre estabelecimento da vontade desse mesmo povo. Segundo Rousseau e Kant, os destinatários do direito também devem entender-se como seus próprios autores".

Portanto, deve haver a compatibilidade entre o regime democrático e os direitos fundamentais para que ocorra a efetiva democracia, conforme expõe Dimitri Dimoulis7, haja vista que, "a democracia é o requisito da garantia jurídica e de efetivo respeito a tais direitos. Por sua vez, esses direitos são pré-requisitos da democracia, permitido ao indivíduo participar dos processos democráticos”.

Ressalta José Joaquim Gomes Canotilho8, em relação à construção do Direito Constitucional no Estado Democrático de Direito: "se ontem a conquista territorial, a colonização e o interesse nacional surgiam como categorias referenciais, hoje os fins dos Estados podem e devem ser os da construção de 'Estados de Direito

\footnotetext{
${ }^{4}$ MULLER, Friedrich. Que grau de exclusão social ainda pode ser tolerado por um sistema democrático in: PIOVESAN, Flávia (Coord.) Direitos Humanos, Globalização Econômica e Integração Regional. Desafios do Direito Constitucional internacional. São Paulo: Max Limonad, 2002. P. 560.

${ }^{5}$ DIMOULIS, Dimitri. Estado nacional, Democracia e Direitos Fundamentais, Conflitos e Aporias. in: CLÈVE, Clèmerson Merlin, SARLET, Ingo Wolfgang. PAGLIARINI, Alexandre Coutinho (Coordenadores). Direitos Humanos e Democracia. Rio de Janeiro: Editora Forense, 2007. p. 30.

${ }^{6}$ HABERMAS, Jürgen. A INCLUSÃO DO OUTRO: estudos de teoria política. Tradução: George Sperber, Paulo Astor Soethe (UFPR), Milton Camargo Mota. São Paulo: Edições Loyola. 2002. p. $135 .{ }^{30}$ HABERMAS, Jürgen. A INCLUSÃO DO OUTRO: estudos de teoria política. Tradução: George Sperber, Paulo Astor Soethe (UFPR), Milton Camargo Mota. São Paulo: Edições Loyola. 2002. p. 135.

${ }^{7}$ DIMOULIS, Dimitri. Estado nacional, Democracia e Direitos Fundamentais, Conflitos e Aporias. in: CLÈVE, Clèmerson Merlin, SARLET, Ingo Wolfgang. PAGLIARINI, Alexandre Coutinho

(Coordenadores). Direitos Humanos e Democracia. Rio de Janeiro: Editora Forense, 2007. p. $31 .{ }^{32}$ HABERMAS, Jürgen. A INCLUSÃO DO OUTRO: estudos de teoria política. Tradução: George Sperber, Paulo Astor Soethe (UFPR), Milton Camargo Mota. São Paulo: Edições Loyola. 2002. p. 135.

${ }^{8}$ CANOTILHO, José Joaquim Gomes. Estudos Sobre Direitos Fundamentais. $1^{\mathrm{a}}$ ed. $3^{\mathrm{a}}$ t. São Paulo: Editora Revista dos Tribunais, 2008. p. 121.
} 
Democráticos, Sociais e Ambientais', no plano interno e Estados abertos e internacionalmente amigos e cooperantes no plano externo".

A democracia se consolida e se forma pela participação popular, a soberania popular, através da qual ocorre a liberdade de expressão, o diálogo, a efetiva análise das questões sociais, formando e estruturando o Estado Social de Direito.

Conforme Elisabete Maniglia, o Estado Social de Direito "no mundo hodierno se constrói em alicerces, voltados para o respeito às normas legais, por ele estabelecido, voltados para o respeito e efetivação de uma ordem social justa, que busque a aplicação dos direitos, chamados de quarta geração9 e que, acima de tudo, respeite e dignifique os direitos fundamentais 10".

Os direitos fundamentais irradiam um limite de direitos a serem observados tanto pelo Estado representado pelo legislador, como pelos cidadãos, provocando um contrapeso entre a soberania estatal e a soberania popular exercida em um Estado democrático de direito.

Ademais, conforme esclarece Jürgen Habermas 11, "o processo legislativo democrático precisa confrontar seus participantes com as expectativas normativas das orientações do bem da comunidade, porque ele próprio tem que extrair sua força legitimadora do processo de um entendimento dos cidadãos sobre regras de sua convivência".

Desta forma em que pese o Estado estar sendo regido através de um regime democrático, pelo qual estabelece suas normas em meio a um processo legislativo livre e soberano, se vê atado às diretrizes fundamentais determinadas na Carta Constitucional.

Os direitos fundamentais, conforme José Martinez de Pisón "são aqueles direitos que aparecem refletidos nos capítulos correspondentes das Constituições e que,

\footnotetext{
${ }^{9}$ PISÓN, José Martínez de. Derechos Humanos: historia, fundamento y realidad. Zaragoza: Editorial Cometa, 1997. pp. 174-176.

${ }^{10}$ MANIGLIA, Elisabete. Algumas reflexões sobre Democracia,direitos Humanos e Questão Agrária.In: ANNONI, Danielle. (org.) Os Novos conceitos do Novo Direito Internacional: cidadania, democracia e Direitos Humanos. Rio de Janeiro, 2002. p. 166.

${ }^{11}$ HABERMAS, Jürgen. Directo e democracia: entre facticidade e validade. V. I. $2^{\mathrm{a}}$ ed. tradução: Flavio Beno Siebeneichle. Rio de Janeiro: Tempo Brasileiro, 2010. p. 115.
} 
portanto, são garantidos por mecanismos de proteção de direito de um país e 'gozam de uma tutela reforçada' 12 ”.

Explica Estefânia Maria de Queiroz Barboza13, se apresentam como mecanismos limitadores "criando uma tensão entre direitos fundamentais e democracia, e, em conseqüência, produzindo também um conflito entre o princípio constitucional e o princípio democrático, visto que os direitos fundamentais criam limites negativos e positivos ao processo democrático".

Para Carl Schmitt14, direitos fundamentais são, "apenas aqueles direitos que constituem o fundamento do próprio Estado e que, por isso e como tal, são reconhecidos pela Constituição".

não pode ser deixada para se decidida por uma simples maioria parlamentar".

Ademais, acrescenta "o Estado Democrático de Direito tem como pilares básicos a democracia e os direitos fundamentais, daí porque incontestável o conteúdo político presente na Carta de 198815".

Diante desta breve análise da relação entre a democracia que, como visto, trata da gênese do conceito de direitos fundamentais, passamos à análise da evolução desses direitos.

\section{A EVOLUÇÃO DOS DIREITOS FUNDAMENTAIS}

Os Direitos Fundamentais como normas de direito se alteram e se adequam de acordo com a evolução da sociedade, porquanto o Direito deve representar os anseios da sociedade, pois é mecanismo de regulação entre os cidadãos componentes da sociedade.

A evolução dos Direitos Fundamentais, mormente quando direcionados efetivamente aos Direitos Humanos, refletem em tal grandeza os anseios da sociedade,

\footnotetext{
12 PISÓN, José Martínez de. Derechos Humanos: história, fundamento y realidad. Zaragoza: Editoriales Cometa, 1997. p. 17.

13 BARBOZA, Estefânia Maria de Queiroz. Jurisdição Constitucional: entre constitucionalismo e democracia. Belo Horizonte: Fórum, 2007. pp.150-151.

${ }^{14}$ SCHMITT, Carl. Verfassungsrehctliche Aufsätze. $2^{\mathrm{a}}$ ed. Berlin: Dumcker \& Humblot, 1973. p. $190 .{ }^{45}$ COMPARATO, Fábio Konder. A afirmação histórica dos direitos humanos. $6^{\mathrm{a}}$. ed. rev. e atual. São Paulo: Saraiva, 2008. p. 140.

15 BARBOZA, Estefânia Maria de Queiroz. Jurisdição Constitucional: entre constitucionalismo e democracia. Belo Horizonte: Fórum, 2007. p.148.
} 
na ótica de Joaquín Herrera Flores16, "se converteram no desafio do século XXI. [...] Ninguém pode negar o gigantesco esforço internacional realizado para se formular juridicamente uma base mínima de direitos que alcance todos os indivíduos e formas de vida que compõem a ideia abstrata de humanidade".

Os direitos fundamentais dependendo do momento histórico social são definidos pelos autores por determinada forma, como explica José Joaquim Gomes Canotilho17, ou seja, há aqueles que "falam de direitos fundamentais, de direitos constitucionais e de determinações constitucionais, enquanto quem se refira a direitos fundamentais de $1^{\text {a }}$. classe, a direitos fundamentais de $2^{\text {a }}$. classe e a direitos fundamentais de $3^{\mathrm{a}}$. classe".

Outros por exemplo, José Martinez de Pisón, Manoel Gonçalves Ferreira Filho, classificam os direitos fundamentais por sua geração considerando a ordem histórico cronológica do desenvolvimento do direito constitucional.

Independente da forma de classificação dos direitos fundamentais, sejam por classe ou geração, são subdivididos da seguinte forma:

a) direitos de primeira geração, também denominados de 'direitos fundamentais de $1^{\text {a }}$. classe'18 que seriam os direitos fundamentais em sentido estrito e neles estão incluídas as liberdades públicas e os direitos e garantias individuais clássicas (direitos civis e políticos), que surgiram a partir da Magna Carta19, conforme esclarece Gustavo Filipe Barbosa Garcia20, “assim, nas Declarações de Direito do século XVIII, ganham destaque os direitos de "liberdade", no sentido de que o Estado deve abster-se de interferir na conduta dos indivíduos";

b) de segunda geração, ou de 'direitos fundamentais de $2^{\mathrm{a}}$. classe' não constituem uma categoria homogênea21, haja vista que correspondem aos direitos

${ }^{16}$ HERRERA FLORES, Joaquin. A reinvenção dos direitos humanos. Tradução de: Carlos Roberto Diogo Garcia; Antônio Henrique Graciano Suxberger; Jefferson Aparecido Dias. Florianópolis: Fundação Boiteux, 2009, p. 29.

${ }^{17}$ CANOTILHO, José Joaquim Gomes. Estudos Sobre Direitos Fundamentais. $1^{\text {a }}$ ed. $3^{\text {a }}$ t. São Paulo: Editora Revista dos Tribunais, 2008. pp. 185-186.

${ }^{18}$ CANOTILHO, José Joaquim Gomes. Estudos Sobre Direitos Fundamentais. $1^{\mathrm{a}}$ ed. $3^{\mathrm{a}}$ t. São Paulo: Editora Revista dos Tribunais, 2008. pp. 185-186.

${ }^{19}$ MORAES, Alexandre de. Direitos Humanos Fundamentais: teoria geral. 4 $4^{\text {a }}$ ed. São Paulo: Atlas, 2002. p. 39.

${ }^{20}$ GARCIA, Filipe Barbosa. Meio ambiente do trabalho no contexto dos direitos humanos fundamentais e responsabilidade civil do empregador. In Revista de Direito do Trabalho. Coordenador Domingos Sávio Zainaghi. Ano 35, nº 136, São Paulo: Revista dos Tribunais. 2009. p. 55.

${ }^{21}$ CANOTILHO, José Joaquim Gomes. Estudos Sobre Direitos Fundamentais. $1^{\mathrm{a}}$ ed. $3^{\mathrm{a}}$ t. São Paulo: Editora Revista dos Tribunais, 2008. pp. 185-186. 
econômicos, sociais e culturais, envolvendo uma prestação positiva do Estado22, como o direito ao trabalho, à educação, à saúde, direitos trabalhistas e previdenciários, bem como os econômicos e culturais garantidores da liberdade das nações e das normas internacional de convivência, surgiram no início do século XX23;

c) de terceira geração, também denominados de 'direitos fundamentais de $3^{\mathrm{a}}$. classe', são muito heterogêneos24, abrangendo direitos e deveres do Estado, então denominados direitos de solidariedade ou fraternidade, que englobam o direito a um meio ambiente equilibrado, uma saudável qualidade de vida, ao progresso, a paz, a autodeterminação dos povos e a outros direitos difusos 25 ;

d) de quarta geração, direito à democracia direta, à informação, ao progresso tecnológico, à bioética e ao pluralismo26.

Os direitos de terceira geração, acrescente-se, envolvem uma nova categoria de direitos que, muitas vezes, tornam-se de difícil positivação nos ordenamentos jurídicos internos dos Estados, vez que não se trata de direitos clássicos, mas que envolvem direitos coletivos, e a sua efetivação depende também da comunidade internacional.

É de se esclarecer que as classificações dos direitos fundamentais, mormente pela expressão "geração" de direitos, vêm sofrendo críticas, pois a utilização do termo "pode dar a falsa impressão de substituição gradativa de uma geração por outra"27, quando, na realidade, "o processo é de acumulação e não de sucessão” 28.

\section{O Meio Ambiente como Direito Fundamental e como "Direito Humano"}

A ideia do meio ambiente global chega até nós provenientes de dois pontos de referência distintos, como se verá a seguir.

\footnotetext{
${ }^{22}$ FERREIRA FILHO, Manoel Gonçalves. Direitos humanos fundamentais. $7^{\mathrm{a}}$ ed. São Paulo: Saraiva, 2005, pp. 49-50.

${ }^{23}$ CAVALCANTI, Themistocles Brandão. Princípios gerais de direito público. $3^{\mathrm{a}}$ ed. Rio de Janeiro: Borsoi, 1966, p. 202.

${ }^{24}$ CANOTILHO, José Joaquim Gomes. Estudos Sobre Direitos Fundamentais. $1^{\text {a }}$ ed. $3^{\text {a }}$ t. São Paulo: Editora Revista dos Tribunais, 2008. pp. 185-186.

${ }^{25}$ MOTA, Leda Pereira. SPITZCOVSKI, Celso. Curso de direito constitucional. $5^{\mathrm{a}}$ ed. São Paulo: Editora Juarez de Oliveira, 2000. pp. 316-317.

${ }^{26}$ PISÓN, José Martínez de. Derechos Humanos: historia, fundamento y realidad. Zaragoza: Editorial Cometa, 1997. pp. 174-176.

${ }^{27}$ MARMELSTEIN, George. Curso de direitos fundamentais. $3^{\text {a }}$. ed. São Paulo: Atlas, 2011, p. 59.

${ }^{28}$ MARMELSTEIN, George. Curso de direitos fundamentais. $3^{\text {a }}$. ed. São Paulo: Atlas, 2011, p. 59.
} 
O primeiro ocorreu a mais de vinte e cinco anos, quando foram vistas imagens da Terra enviadas do espaço sideral, fato que levou o homem a observar o nosso planeta como uma entidade total e despertou em muitos a consciência planetária.

A partir disso, surgiu a impressão de que todos os membros deste lindo planeta azul estavam interrelacionados e no interior de uma intrincada teia de vida, que provavelmente não existe em nenhum outro ponto do universo29, trazendo um grau enorme de dependência para com o ambiente em que vivemos.

O segundo ocorreu quando as condições de vida e de trabalho começaram rapidamente a se modificar, como a tecnológica, o alto grau de desenvolvimento de alguns países, as condições de vida e trabalho que, em todos os lugares, fizeram eclodir o fenômeno da globalização.

A nova divisão transnacional do trabalho e da produção transforma o mundo em uma fábrica global, ou seja, o meio ambiente de produção é o planeta, não há divisão de fronteiras, mas a competição transforma o mundo em uma fábrica global, em que o lucro é incessantemente perseguido.

Verifique-se que o direito ao meio ambiente somente passou a ser percebido a partir da década de 1970, quando surgiram os primeiros movimentos de preocupação com a interação entre a utilização dos recursos ambientais (ar, água, solo) e a degradação destes, haja vista a influência direta nas reservas alimentares e na alteração da densidade populacional30.

A consciência quanto aos cuidados e o direito ao meio ambiente saudável de modo a se evitar a degradação permanente, somente se fizeram presente a partir da Conferência das Nações Unidas sobre o Ambiente Humano, realizado em Estocolmo, na Suécia, em 1972, quando então, do encontro, resultou a Declaração sobre o Ambiente Humano, que apresentou como primeiro princípio: "o homem tem o direito fundamental à liberdade, à igualdade, e ao gozo de condições de vida adequada num meio ambiente de tal qualidade que lhe permita levar uma vida digna e gozar do bem-estar", e o texto do princípio é complementado com uma obrigação para o homem que: "tem a solene obrigação de proteger e melhorar o meio ambiente para as gerações presentes e

$$
\text { futuras..." } 68 \text {. }
$$

\footnotetext{
${ }^{29}$ O'SULLIVAN, Edmund. Aprendizagem transformadora uma visão educacional para o século XXI. São Paulo, Cortez: Instituto Paulo Freire, 2004, p. 179.

${ }^{30}$ FALK, Richard. Globalização Predatória: uma crítica. Lisboa: Instituto Piaget, 1999. p. 40-41. ${ }^{68}$ FERREIRA FILHO, Manoel Gonçalves. Direitos humanos fundamentais. $7^{\mathrm{a}}$ ed. São Paulo: Saraiva, 2005 , p. 80.
} 
O movimento ambientalista para o ajustamento de todos os países com vistas à diminuição da camada de ozônio e se evitar o aquecimento global, somente passou a ser levado em consideração a partir da década de 1980, quando, pelo "novo pendor verde da Sra. Thatcher", a Grã-Bretanha se mostrou favorável ao combate à redução das emissões do gás CFC31. Este foi o ponto inicial, mas se seguiram diversos movimentos como em 1992 - Conferência das Nações Unidas para o Ambiente e o Desenvolvimento (CNUAD) ocorrida no Brasil.

Ocorreu uma crescente conscientização da problemática ambiental, e a sociedade passou a exigir condutas mais responsáveis, mormente após a ocorrência de algumas grandes catástrofes (acidentes de Bopahl na Índia, Chernobyl na ex-URSS, e o de Three Miles Island nos EUA) e das evidências científicas dos efeitos relativos às modificações provocadas pelo homem no frágil equilíbrio da vida no planeta, causando grandes problemas ambientais, levando-se em consideração que, se não existirem o cuidado e a manutenção do meio ambiente saudável, o ser humano corre o sério risco de extinção.

Cita-se, a observação de Délton Winter de Carvalho32, relativo à evolução da sociedade e as suas conseqüências: "desde meados do século $\mathrm{XX}$ pode ser constatado que as aquisições evolutivas e as instituições sociais da Sociedade Industrial enfrentam a possibilidade, sem precedentes históricos, da destruição da vida no planeta, no que é descrito por Ulrich Beck como uma modernização reflexiva".

Complementa o seu pensamento esclarecendo a razão da modernidade reflexiva, uma vez que a: "a sociedade passa a ter de encarar e lidar com os riscos que esta própria produz". Ou seja, a sociedade em razão de sua evolução, [...] em direção a uma modernidade em que o êxito do capitalismo industrial geral uma autoconfrontação da sociedade industrial com suas próprias consequências: o surgimento de riscos globais, imprevisíveis, incalculáveis, invisíveis, transtemporais, tais como é o caso paradigmático de Chernobyl" 33.

Diante dos riscos a que o homem está se submetendo, e com o intuito de proteção à sua própria sobrevivência, desenvolve direitos que para sua concretização são recepcionados através de normas fundamentais.

\footnotetext{
${ }^{31}$ FALK, Richard. Globalização Predatória: uma crítica. Lisboa: Instituto Piaget, 1999. p. 41.

32 CARVALHO, Délton Winter de. Dano ambiental futuro: a responsabilização civil pelo risco ambiental - responsabilidade civil, vol. V. São Paulo: Revista dos Tribunais, 2010, p. 1053.

${ }^{33}$ CARVALHO, Délton Winter de. Dano ambiental futuro: a responsabilização civil pelo risco ambiental - responsabilidade civil, vol. V. São Paulo: Revista dos Tribunais, 2010, p. 1053.
} 
Portanto, é de se considerar direito fundamental aquele que recebe proteção constitucional, ou seja, direitos garantidos e limitados no tempo e no espaço, "objetivamente vigentes numa ordem jurídica concreta"34.

Aliado ao que cita Gabriela Soldano Garcez73, "um direito somente será considerado fundamental quando sua inobservância implicar na impossibilidade de exercer o direito à vida, ou seja, aquele direito (fundamental) deve ser essencial para o exercício do mais fundamental dos direitos, o direito à vida". Completando a citação: "se o meio ambiente é essencial para a manutenção e sobrevivência do planeta e da raça humana, este é dotado de uma prerrogativa imprescindível para que cada cidadão possa exercer com plenitude o direito à vida"74, consequentemente, "todos os direitos ligados à vida são, portanto, direitos fundamentais".

Portanto, o direito ao meio ambiente está elencado como direito de terceira "classe" ou "geração", haja vista estar diretamente "ligado a vida", e "as alterações provocadas neste meio de alguma forma afeta a todos, sejamos ou não conscientes dele, haja vista que seus efeitos ultrapassam as fronteiras nacionais e qualquer barreira estabelecida pelo homem"35.

Na explicação de Gomes e Bulzico, "cumpre alertar que o meio ambiente ecologicamente equilibrado, antes de ser considerado um direito humano, deve ser compreendido como uma prerrogativa para a vida na Terra"36.

Consequentemente, quando se fala em proteção ao meio ambiente, se está envolvendo questões que envolvem direitos não de apenas um indivíduo, ou de uma comunidade, mas o direito de todas as pessoas ao mesmo tempo, haja vista que uma atividade desenvolvida em um local pode refletir em outro, e comprometer a sobrevivência da vida humana no Planeta Terra.

Destarte, o que se verifica é um alargamento dos Direitos humanos, haja vista que os Tratados que envolvem a proteção ao meio ambiente, podem de forma direta influir na ampliação, da proteção aos direitos internos nacionalmente garantidos.

\footnotetext{
${ }^{34}$ CANOTILHO, José Joaquim Gomes. Direito Constitucional. 6. ed. Coimbra: Almedina, 1993. p. 529.

${ }^{73}$ GARCEZ, Gabriela Soldano. Do direito fundamental ao meio ambiente de trabalho equilibrado. In Revista Direitos Fundamentais \& Democracia. v. 10, n. 10. Curitiba: Unibrasil, jul./dez. 2011. p. $326 .{ }^{74}$ GARCEZ, Gabriela Soldano. Do direito fundamental ao meio ambiente de trabalho equilibrado. In Revista Direitos Fundamentais \& Democracia. v. 10, n. 10. Curitiba: Unibrasil, jul./dez. 2011. p. 326.

${ }^{35}$ PISON, José Martínez. Derechos Humanos: história, fundamento y realidad. Zaragoza: Editoriales Cometa, 1997, p. 205.

${ }^{36}$ GOMES, Eduardo Biacchi. BULZICO, Bettina Augusta Amorim. Soberania, Cooperação e o Direito Humano ao Meio Ambiente. In Sustentabilidade, desenvolvimento e democracia. Organizadores: Eduardo Biacchi Gomes e Bettina Augusta Amorim Bulzico. Ijuí: Editora Unijuí, 2010. p. 50.
} 
Conforme explica, de forma sintética, Karina Houat Harb37, "o respeito ao direito do meio ambiente equilibrado implica, necessariamente, na defesa do direito à vida, que é o mais básico dos direitos fundamentais", e esclarece o seu pensamento haja vista que, "nele se inserindo por visar diretamente à qualidade de vida (artigo 225, caput, da $\mathrm{CF} / 88$ ) como meio de atingir a finalidade de preservação e proteção à existência, em qualquer forma que esta se manifeste, bem como condições dignas de existência à presente e às futuras gerações".

\section{CONCLUSÃO: ADPF 101/DF E O CASO DOS REMOLDADOS}

A formação do Estado constitucional de direito está ligada a concepção de democracia e de proteção aos direitos fundamentais, assim como em relação aos demais direitos que tutelados pela Constituição da República Federativa do Brasil, como é o caso da proteção ao meio ambiente.

Como visto no presente artigo, a proteção a um meio ambiente ecologicamente equilibrado é norma constitucional e, assim, a República Federativa do Brasil deve adotar todas as políticas voltadas a cumprir com tais objetivos, quer aquelas constantes na constituição, leis, tratados e decisões dos tribunais internacionais.

A Ação de Descumprimento de Preceito Fundamental de n. 101 (Distrito Federal), julgada no ano de 200938, bem demonstra a realidade internacional a qual o Brasil encontra-se inserido, especialmente em relação a proteção ao meio ambiente. Naquela ação proibiu-se a importação dos pneus remoldados, reconhecendo-se a constitucionalidade dos atos normativos que vedam tais condutas, tendo em vista a necessidade de proteger o meio ambiente e buscar a formação de um meio ambiente ecologicamente equilibrado.

Aquele acórdão fez alusão ao contencioso interposto pela União Europeia contra o Brasil dentro da Organização Mundial do Comércio, referente a decisão daquela Organização Internacional que entendia ser lícita a conduta brasileira de proibir a importação de carcaças de pneus, tendo em vista a formação do grande passivo ambiental.

\footnotetext{
37 HARB, Karina Houat. Direitos humanos e meio ambiente. In Revista da Associação dos Pósgraduandos da Pontifícia Universidade Católica de São Paulo. Ano III, n. 16, 1998. p. 78

${ }^{38}$ http://www.stf.jus.br/portal/jurisprudencia/listarJurisprudencia.asp?s1=\%28importa\%E7\%E3o+e+remo

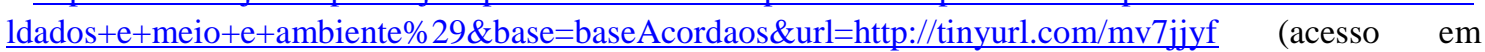
16.06.2014)
} 
Assim, tornou-se necessário proibir a importação de carcaças de pneus, tendo em vista a multiplicidade de decisões contraditórias até então existentes no judiciário brasileiro.

Da mesma forma o acórdão reconheceu a legalidade de importação dos pneus remoldados integrantes dos Estados partes do Mercosul, tendo em vista a existência de decisão existente dentro do tribunal ad hoc.

O acórdão em questão fez expressa referência ao contencioso interposto pela União Europeia em face da República Federativa do Brasil, cuja decisão do relatório apontou por afastar os argumentos do bloco europeu e reconhecer a tese brasileira, no sentido de que a proibição de importar as carcaças de pneus justificam-se por força do artigo XX do GATT (Acordo Geral de Tarifas e Comércio) e que assevera ser lícito ao Estado proibir o ingresso de mercadorias em seu território, na hipótese de causar dano à saúde animal, vegetal ou humana (meio ambiente).

A República Federativa do Brasil, enquanto Estado democrático de direito e inserido dentro do mundo globalizado, como parte em tratados sobre livre comércio e membro de Organizações Internacionais, deve cumprir com as decisões proferidas pelos tribunais internacionais e tratados devidamente ratificados (tendo em vista a aplicação do princípio pacta sunt servanda e o primado do direito internacional frente o direito interno39).

No caso específico, o que se verifica é que em um mundo globalizado torna-se cada vez mais presente a interferência da ordem jurídica internacional junto aos ordenamentos jurídicos dos Estados, o que se traduz em um verdadeiro diálogo entre jurisdições e a necessidade de o Supremo Tribunal Federal observar os tratados devidamente ratificados e as decisões proferidas pelos tribunais internacionais (no caso específico órgão de solução de controvérsias da OMC e tribunal arbitral do Mercosul).

Finalmente, verifica-se que dentro do chamado diálogo entre jurisdições (internacional e nacional), tem-se o chamado controle de convencionalidade realizado pelo Supremo Tribunal Federal em temas afetos ao meio ambiente, que se trata de uma preocupação global.

\footnotetext{
39 Artigos 26 e 27 da Convenção de Viena sobre Direito dos Tratados, 1969.
} 


\section{REFERÊNCIAS}

ALEXY, Robert. Teoria dos Direitos Fundamentais. Tradução: Virgílio Afonso da Silva. São Paulo: Malheiros, 2011.

ARAUJO, Nadia. Direito Internacional Privado. Rio de Janeiro: Renovar, 2011.

ARON, Raymond. As etapas do pensamento sociológico. tradução: Sérgio Bath. $7^{\text {a }}$ ed. São Paulo: Martins Fontes, 2008.

BARBOZA, Estefânia Maria de Queiroz. Jurisdição Constitucional: entre constitucionalismo e democracia. Belo Horizonte: Fórum, 2007.

Jurisdição Constitucional, Direitos Fundamentais e Democracia. in: CLÈVE, Clèmerson Merlin, SARLET, Ingo Wolfgang. PAGLIARINI, Alexandre Coutinho (Coordenadores). Direitos Humanos e Democracia. Rio de Janeiro: Editora Forense, 2007.

Stare decisis, integridade e segurança jurídica: reflexões críticas a partir da aproximação dos sistemas de common law e civil law. Tese de Doutorado, PUCPR, 2011.

CARVALHO, Délton Winter de. Dano ambiental futuro: a responsabilização civil pelo risco ambiental - responsabilidade civil, vol. V. São Paulo: Revista dos Tribunais, 2010.

CAVALCANTI, Themistocles Brandão. Princípios gerais de direito público. $3^{\text {a }}$ ed. Rio de Janeiro: Borsoi, 1966.

CANOTILHO, José Joaquim Gomes. Direito Constitucional e teoria constitucional. $2^{\mathrm{a}}$ Ed. Coimbra: Almedina, 1998.

Estudos Sobre Direitos Fundamentais. $1^{a}$ ed. $3^{a}$ t. São Paulo: Editora Revista dos Tribunais, 2008.

COMPARATO, Fábio Konder. A afirmação histórica dos direitos humanos. $6^{\mathrm{a}}$. ed. rev. e atual. São Paulo: Saraiva, 2008.

DIMOULIS, Dimitri. Estado nacional, Democracia e Direitos Fundamentais, Conflitos e Aporias. in: CLÈVE, Clèmerson Merlin, SARLET, Ingo Wolfgang. PAGLIARINI, Alexandre Coutinho (Coordenadores). Direitos Humanos e Democracia. Rio de Janeiro: Editora Forense, 2007.

DWORKIN, Ronald. O direito da liberdade: a leitura moral da Constituição norteamericana. São Paulo: Martins Fontes, 2006.

O Império do Direito. São Paulo: Martins Fontes, 2007.

DUARTE, Écio Oto Ramos; POZZOLO, Susanna. Neoconstitucionalismo e positivismo jurídico: as faces da teoria do directo em tempos de interpretação moral da constituição. São Paulo: Landy Editora, 2006. 
FALK, Richard. Globalização Predatória: uma crítica. Lisboa: Instituto Piaget, 1999. FERREIRA FILHO, Manoel Gonçalves. Direitos humanos fundamentais. 13 ${ }^{\mathrm{a}}$ ed. São Paulo: Saraiva. 2011.

FIORAVANTI, Maurizio. Estado Y constitución. In: FIORAVANTI, M (Org.). In. El Estado Moderno en Europa: Instituciones Y derecho. Madrid: Editorial Trotta, 2004.

GARCEZ, Gabriela Soldano. Do direito fundamental ao meio ambiente de trabalho equilibrado. In Revista Direitos Fundamentais \& Democracia. v. 10, n. 10. Curitiba: Unibrasil, jul./dez. 2011.

GARCIA, Filipe Barbosa. Meio ambiente do trabalho no contexto dos direitos humanos fundamentais e responsabilidade civil do empregador. In Revista de Direito do Trabalho. Coordenador Domingos Sávio Zainaghi. Ano 35, $\mathrm{n}^{\circ}$ 136, São Paulo: Revista dos Tribunais. 2009.

GOMES, Eduardo Biacchi. BULZICO, Bettina Augusta Amorim. Soberania, Cooperação e o Direito Humano ao Meio Ambiente. In Sustentabilidade, desenvolvimento e democracia. Organizadores: Eduardo Biacchi Gomes e Bettina Augusta Amorim Bulzico. Ijuí: Editora Unijuí, 2010.

HABERMAS, Jürgen. A INCLUSÃO DO OUTRO: estudos de teoria política. Tradução: George Sperber, Paulo Astor Soethe (UFPR), Milton Camargo Mota. São Paulo: Edições Loyola. 2002.

Directo e democracia: entre facticidade e validade. V. I. $2^{\text {a }}$ ed. tradução: Flavio Beno Siebeneichle. Rio de Janeiro: Tempo Brasileiro, 2010.

HARB, Karina Houat. Direitos humanos e meio ambiente. In Revista da Associação dos Pós-graduandos da Pontifícia Universidade Católica de São Paulo. Ano III, n. 16, 1998.

HERRERA FLORES, Joaquin. A reinvenção dos direitos humanos. Tradução de: Carlos Roberto Diogo Garcia; Antônio Henrique Graciano Suxberger; Jefferson Aparecido Dias. Florianópolis: Fundação Boiteux, 2009.

HOBSBAWN. Eric J. Nações e Nacionalismo desde 1780: programa, mito e realidade. tradução: Maria Celia Paoli, Anna Maria Quirino. Rio de Janeiro: Paz e Terra, 2008.

HOUAISS, Antonio. Dicionário eletrônico. Rio de Janeiro, Objetiva, 2012, CD-rom.

HUNT, Lynn. A invenção dos direitos humanos: uma história. Tradução Rosaura Eichenberg. São Paulo: Companhia das Letras. 2009.

MANIGLIA, Elisabete. Algumas reflexões sobre Democracia,direitos Humanos e Questão Agrária.In: ANNONI, Danielle. (org.) Os Novos conceitos do Novo Direito Internacional: cidadania, democracia e Direitos Humanos. Rio de Janeiro, 2002.

MARMELSTEIN, George. Curso de direitos fundamentais. $3^{\text {a }}$. ed. São Paulo: Atlas, 2011. 
MENDES, Gilmar Ferreira. Curso de Direito Constitucional. São Paulo: Saraiva, 2008.

MORAES, Alexandre de. Direitos Humanos Fundamentais: teoria geral. 4a . ed. São Paulo: Atlas, 2002.

MOTA, Leda Pereira. SPITZCOVSKI, Celso. Curso de direito constitucional. $5^{\mathrm{a}}$ ed. São Paulo: Editora Juarez de Oliveira, 2000.

MULLER, Friedrich. Que grau de exclusão social ainda pode ser tolerado por um sistema democrático in: PIOVESAN, Flávia (Coord.) Direitos Humanos, Globalização Econômica e Integração Regional. Desafios do Direito Constitucional internacional. São Paulo: Max Limonad, 2002. p. 560..

NINO, Carlos Santiago. La Constitución de La democracia deliberativa. Barcelona: Gedisa, 1997.

O’SULLIVAN, Edmund. Aprendizagem transformadora uma visão educacional para o século XXI. São Paulo, Cortez: Instituto Paulo Freire, 2004.

PAGLIARINI, Alexandre Coutinho (Coordenadores). Direitos Humanos e Democracia. Rio de Janeiro: Editora Forense, 2007.

PISÓN, José Martínez de. Derechos Humanos: história, fundamento y realidad. Zaragoza: Editoriales Cometa, 1997.

SCHMITT, Carl. Verfassungsrehctliche Aufsätze. $2^{\text {a }}$ ed. Berlin: Dumcker \& Humblot, 1973.

Verfassungslehre. Berlin:Duncker \& Humblot, 1993.

SOARES, Mário Lúcio Quintão. A metamorfose da soberania em face da mundialização. In PIOVESAN, Flávia (Coord.) Direitos Humanos, Globalização Econômica e Integração Regional. Desafios do Direito Constitucional internacional. São Paulo: Max Limonad, 2002. 